\title{
Aplicação da análise da conversa etnometodológica em entrevista de seleção: considerações sobre o gerenciamento de impressões
}

\author{
Caroline Benevenuti Passuello \\ Ana Cristina Ostermann \\ Universidade do Vale do Rio dos Sinos
}

\begin{abstract}
Resumo
A entrevista de seleção é descrita como um evento no qual indivíduos buscam controlar impressões que outros formam a seu respeito no que tange a comportamentos, crenças e atributos pessoais. Este artigo analisa aspectos interacionais que podem estar relacionados ao gerenciamento de impressões por parte do entrevistado em uma entrevista de seleção. Para tanto, uma entrevista de seleção foi gravada e transcrita, e utilizou-se a análise da conversa etnometodológica como instrumental analítico. A análise revela a assimetria de papéis discursivos entre entrevistado e entrevistador e para fenômenos interacionais que evidenciam o gerenciamento de impressão por parte do entrevistado: (1) aumento de velocidade de fala quando se refere à sua demissão ou a outro evento percebido como negativo; (2) co-construção de turnos como forma de o entrevistado antecipar que conhece os pontos apresentados pelo entrevistador; (3) explicações (accounts) como modo de o candidato prevenir inferências negativas a seu respeito.
\end{abstract}

Palavras-chave: entrevista de seleção; gerenciamento de impressão; análise da conversa etnometodológica

\begin{abstract}
Applying ethnomethodological conversation analysis to job interviews: considerations about impression management. Job interviews have been described as events in which individuals aim at managing the impressions others get from them with regards to one's attitudes, beliefs and personal character. This paper analyzes some interactional aspects that might be related to impression management by a candidate during a job interview. In order to accomplish that, a job interview was audiorecorded and transcribed, and the conversation analysis tools were used to analyze the data. The analysis shows the asymmetry of discursive roles between interviewee and interviewer and the interactional phenomena through which impression management is substantiated by the job candidate: (1) faster delivery of the speech when the candidate refers to being previously fired or to some other event which might be seen as negative; (2) turn co-construction as a way for the candidate to anticipate that he knows the aspects being discussed by the job interviewer; (3) explanations (accounts) as a way of preventing negative inferences about himself.

Keywords: job interview; impression management; conversation analysis
\end{abstract}

People perform actions of different kinds through their talk [...] and they accomplish the nature of these actions partly through constructing their discourse out of a range of styles, linguistic resources and rhetorical devices. (Potter \& Wetherell, 1994)

$\mathrm{N}$ a condição de participantes em interações com uma ou mais pessoas, indivíduos introduzem e sustentam mensagens e identidades (Ribeiro \& Garcez, 2002). Interações face a face que ocorrem em ambientes institucionais também se destacam pela complexidade das relações de poder e dos papéis sociais que invocam. Conforme aponta Heller (2001), "instituições são locais de seleção social e de regulação e distribuição de bens de valor" (p. 256), ou seja, são locais onde um/a representante institucional tem algum poder de decisão sobre outra pessoa.
Entrevistas de seleção para emprego inserem-se exatamente nessa descrição, visto que decisões daí decorrentes podem impactar direta e profundamente vidas e carreiras de candidatos. Nesse contexto, com objetivo de serem aprovados em tais processos seletivos, candidatos tendem a apresentar características e atributos pessoais que julgam positivos e minimizar outros que sentem como inadequados, gerenciando, dessa forma, as impressões que entrevistadores e outros responsáveis por sua seleção/contratação possam ter a seu respeito (Almeida, 2004; Carvalho \& Grisci, 2002; Mendonça \& Amantino-de-Andrade, 2003; Silveira, 2002).

Assim, o conceito de gerenciamento de impressões em entrevistas de seleção faz-se um tema pertinente e atual, na medida em que revela a dinâmica existente em seleções de candidatos a 
empregos, trazendo à tona a subjetividade desses, bem como os artifícios que utilizam para transmitir as imagens pessoais que julgam adequadas. Contudo, há escassez de estudos de caráter interdisciplinar, que focalizem não apenas $o$ quê é dito pelos interagentes em uma entrevista de seleção, mas como as coisas são ditas e interpretadas.

Com vistas a aprofundar os conhecimentos teóricoempíricos sobre o tema e alargar as possibilidades de aparatos metodológicos para investigá-lo, optou-se por tratar a questão do gerenciamento de impressões neste estudo a partir da análise da fala-em-interação que se dá entre entrevistado e entrevistador. Utilizando-se do instrumental analítico oferecido pela análise $d a$ conversa etnometodológica (Drew, 2003; Hutchby \& Wooffitt, 1998; Schegloff, 1997), este artigo objetiva apresentar os aspectos interacionais que podem estar relacionados ao gerenciamento de impressões por parte do entrevistado no momento da entrevista. Dessa forma, busca-se também demonstrar a produtividade metodológica da análise da conversa etnometodológica para estudos na área de Psicologia.

\section{Referencial teórico}

Entrevistas de seleção de candidatos a emprego vêm sendo estudadas tendo em vista suas vicissitudes. Segundo Button (1992), sua relevância dá-se tendo em vista dois eixos: a categorização específica das pessoas que fazem parte dessa situação (entrevistador e entrevistado ${ }^{1}$ ) e o contexto em que ocorre (busca por emprego). Em uma entrevista de seleção de candidato a emprego, portanto, encontram-se pessoas com papéis diferenciados: enquanto ao entrevistador cabe fazer perguntas para o entrevistado, a este cabe respondê-las, tendo como objetivo ser aprovado para preencher uma vaga em determinada organização.

Os papéis desempenhados na entrevista podem ser analisados a partir de seu próprio contexto, pois, como Levinson (1992) sugere, a entrevista é composta de seqüências de falas tecnicamente conhecidos como turnos de fala - de perguntas e respostas. Turnos de fala podem ser definidos como enunciados de sentido completo, que podem variar desde enunciados contendo uma palavra, como sim, ou mesmo ahãm, até enunciados bem mais longos e sintaticamente complexos.

Schneider (2000) aponta o fato de entrevistas serem uma tarefa realizada em conjunto, na qual ambas as partes envolvidas (entrevistador e entrevistado) constroem o conhecimento que é explicitado. Segundo a autora, "entrevistadores não são mais entendidos simplesmente como condutores para respostas, mas como altamente envolvidos na produção das respostas" (p. 162).

Fica claro, a partir de tal asserção, que a forma como é conduzida a interação que se dá entre entrevistado e entrevistador gera conseqüências na construção do evento como um todo, e que a atividade do entrevistador não se reduz à obtenção de respostas por parte do entrevistado. De outra forma, o entrevistador possui um papel de co-produtor das respostas do entrevistado. Assim, em uma perspectiva sócio-interacional (na qual as identidades são compreendidas como emergentes nas interações e não simplesmente determinadas por aspectos de personalidade), as ações do entrevistador são também analisadas como influentes na entrevista e nos tipos de respostas providas.

Apesar de ser uma atividade construída de forma conjunta, é clara a assimetria de papéis desempenhados entre as partes envolvidas em entrevistas de seleção. Segundo Clegg (1996), "o poder intervém sempre ao mesmo tempo internamente na hierarquia e na linguagem, na dominação e no simbólico" (p. 49). Scheuer (2001) discute essa situação, apresentando dados levantados por sociolingüistas e psicólogos, e confronta-os com os saberes das ciências administrativas:

Embora alguns autores no campo da teoria administrativa considerem o fato de fazer perguntas como um dos modos de obter uma relativa simetria na interação (...), autores do campo da sociolingüística e da psicologia social argumentam que fazer perguntas impõe várias formas de controle social e interacional sobre o entrevistado. (p. 228)

Nessa relação assimétrica, o julgamento ao qual o entrevistado está exposto traz conseqüências imediatas e significativas para sua vida e carreira, ficando evidente o poder de gatekeeping ${ }^{2}$ (Erickson \& Shultz, 1982) do entrevistador, que pode determinar a contratação de um candidato. Assim, muitas vezes, candidatos buscam controlar as impressões que os entrevistadores têm a seu respeito, no que tange a comportamentos, crenças e atributos pessoais. Essa tentativa de controle deriva, sobretudo, da própria situação: buscando serem escolhidos para um emprego, candidatos procuram mostrar o que têm de melhor e esconder ou disfarçar pontos sentidos como não tão adequados, buscando gerenciar as impressões que outros indivíduos possam ter a seu respeito.

A tentativa de indivíduos de dirigir e dominar impressões que outros possam ter foi descrita por Irving Goffman (1985), quando utilizou a metáfora da ação teatral para apresentar o comportamento humano. Conforme tal autor, em diversas situações sociais, as pessoas comportam-se tal como atores que representam personagens diante do público. Assim, os atores sociais criam efeitos dramáticos ao gerenciarem a apresentação de seu eu (self-presentation) em múltiplas situações.

Esse fenômeno é denominado gerenciamento de impressões, processo por meio do qual as pessoas comportam-se de modos específicos para criar uma imagem social desejada, tentando controlar as impressões que os outros têm delas em relação a comportamentos, motivações, moralidade e atributos pessoais (Mendonça \& Amantino-de-Andrade, 2003).

Dentre as diversas técnicas utilizadas para gerenciar impressões, salientam-se como estratégias (comportamentos que influenciam impressões de longo prazo): a autopromoção, a exemplificação, a insinuação, a suplicação e a intimidação; e, como táticas (comportamentos que influenciam impressões a curto prazo): a autodescrição, a exclusão, a exposição de atitudes, a justificativa, as atribuições públicas, o comportamento não-verbal, as associações sociais, a concordância e o ambiente físico (Almeida, 2004).

Silveira (2002), analisando especificamente o contexto da entrevista de seleção, aponta que o candidato tende a utilizar diversas formas para dizer coisas positivas sobre si: ter sido promovido, estar na profissão por vocação, ter permanecido no emprego por um bom espaço de tempo, ter sido selecionado 
entre muitos candidatos em empregos anteriores e estar bem informado sobre as rotinas do cargo ${ }^{3}$. Essa autora ainda salienta que, durante uma entrevista de emprego, candidatos tendem a monitorar duas coisas: o tópico e o point. Enquanto o primeiro corresponde à pergunta sobre o que se fala?, o segundo refere-se a onde você quer chegar?.

Essa tentativa de controle também foi estudada por meio da fala-em-interação entre entrevistado e entrevistador, tendo como abordagem de análise a análise da conversa etnometodológica. Silveira (2002), por exemplo, destaca a forma como entrevistadores e candidatos a emprego recorrem a estratégias discursivo-interacionais para desempenharem seus papéis discursivos e as ações tópicas previstas no contexto institucional das entrevistas de emprego. A autora pontua que o discurso produzido nessa atividade de fala deve ser visto como estando encaixado em contextos mais amplos: os contextos institucional e sociocultural em que ocorrem. Da mesma forma, Drew (2003) aponta que ambientes institucionalizados produzem falas e interações diferentes daquelas produzidas em conversações mundanas.

Conforme Jaworski e Coupland (1999), a comunicação é entendida como um processo ritualizado que permite aos participantes construir e projetar versões desejáveis de suas identidades, em uma sucessão de performances direcionadas a públicos específicos: "o comportamento de um participante define e constrói relações sociais e de identidades para os outros membros do grupo" (p. 407).

Scheuer (2001) também apresenta estudos sobre as práticas discursivas de candidatos e entrevistadores, observando que as entrevistas bem sucedidas refletem a amplitude do repertório estilístico do candidato (estilo comunicativo - modo de interagir verbalmente). Um dos achados dessa autora é que o número de palavras usadas é maior nas respostas de quem passou nas entrevistas. Assim, conclui a pesquisadora, o sucesso em entrevistas de emprego depende mais das categorias sociais do que das competências individuais.

\section{Método}

Este estudo consiste em uma pesquisa qualitativa de caráter exploratório, que busca apresentar os aspectos interacionais que podem relacionar-se ao gerenciamento de impressões. Para tanto, uma entrevista de seleção para o cargo de executivo de vendas foi gravada em fita cassete e transcrita conforme convenções sugeridas por Schnack, Pisoni e Ostermann (2005), que podem ser apreciadas em detalhe no Anexo.

Em consonância com os princípios éticos envolvidos em uma pesquisa desta ordem, foi solicitado aos participantes seu consentimento para participar da pesquisa. De forma a proteger suas identidades, seus nomes foram trocados por nomes fictícios, e foi omitido o nome da empresa em que o candidato trabalhava anteriormente, sendo essa representada por VVVV cada vez que mencionada.

Com vistas a atenuar a interferência das pesquisadoras no processo da entrevista, o gravador e a fita foram deixados com a entrevistadora e retirados, posteriormente, em horário combinado. A entrevista foi realizada em uma consultoria de recursos humanos, especializada em recrutamento, seleção e recolocação de pessoal, onde trabalha a entrevistadora.

Como abordagem de análise, utilizou-se a análise da conversa etnometodológica, uma vez que estabelece uma interface única entre a lingüística e outras áreas das ciências sociais, como a sociologia e a psicologia social (Hutchby \& Wooffitt, 1998). Essa abordagem, sobre a qual se discorrerá a seguir, parece bastante adequada aos propósitos deste estudo, pois permite compreender o fenômeno do gerenciamento de impressões por meio de indícios lingüísticos e paralingüísticos em uma entrevista de seleção.

\section{Alguns pressupostos da análise da conversa etnometodológica}

A abordagem teórico-analítica a ser utilizada nesta investigação é a da análise da conversa etnometodológica (Pomerantz \& Fehr, 1997; Sacks, 1992; Ten Have, 1999; Wetherell, 1998; Wooffitt, 2005), também conhecida como microsociologia das interações ou microetnografia. Essa perspectiva caracteriza-se por buscar compreender os métodos utilizados pelos próprios atores sociais enquanto desempenham seus diferentes papéis (como, por exemplo, de entrevistador e de entrevistado).

Conforme explica Ostermann (2006), nessa abordagem se estuda a fala das pessoas propriamente dita e não seus pensamentos, emoções, atitudes, crenças ou experiências de vida, que são assumidos como subjacentes à fala (e que podem ser expressos por meio dela). A perspectiva da análise da conversa etnometodológica trata da fala como uma forma de ação social, ou seja, como uma forma de fazer coisas no mundo (discordar, reclamar ou apresentar uma identidade em particular).

Assim, a análise da conversa de base etnometodológica investiga como as pessoas envolvidas em uma interação compreendem o que sua fala está fazendo. Por exemplo, o turno de fala "Está quente aqui" pode ser compreendido como uma simples avaliação da temperatura ambiente ou como um pedido, ainda que indireto, para que se abra uma janela. A um analista será disponibilizada a compreensão de como esse enunciado foi entendido pelos participantes a partir da ação/fala que seguir a ele (por exemplo, "É mesmo." ou "Eu vou abrir uma das janelas."). Assim, as compreensões feitas pelos participantes são disponibilizadas e comunicadas na fala em si (Wilkinson, 2003, p. 94).

Em consonância com a perspectiva teórico-analítica aqui proposta, os dados utilizados para esta pesquisa são naturalísticos, ou seja, são analisados os fatos, as situações que ocorreram e que ocorreriam no dia-a-dia dos participantes sem a intervenção das pesquisadoras. Dessa forma, não foram criados instrumentos de coleta de dados como questionários, entrevistas ou experimentos com intervenções.

A fala de ocorrência natural, como a investigada aqui, conforme explica Potter (2004, p. 205), pode ser definida como linguagem falada produzida de forma completamente independente de ações do/a pesquisador/a, seja ela a linguagem de conversas corriqueiras ao telefone, de reuniões de trabalho ou de interações em entrevistas de emprego. Há um movimento intencional de afastamento de dados do tipo de laboratório (tais 
como as entrevistas post-factum) e de aproximação de interações mais reais, que acontecem no mundo "lá fora" e que aconteceriam com ou sem a proposta de uma pesquisa sobre elas.

Uma importante assunção para a análise da conversa etnometodológica é que as interações no mundo são um fato social (Ostermann, 2006). Daí a necessidade de estudar a fala nas práticas sociais. $\mathrm{O}$ foco de atenção não é a linguagem na condição de um sistema abstrato de regras, mas a linguagem é tomada como o meio para interação. A análise da conversa de base etnometodológica torna-se, assim, a análise do que as pessoas fazem de fato, de suas ações por meio da linguagem (Potter, 2004, p. 203).

É importante esclarecer a razão pela qual as interações analisadas dentro dessa perspectiva precisam, necessariamente, ser gravadas em áudio. Diferentemente de pesquisas que se centram no conteúdo das falas ou apenas no que foi dito, estudos de análise da conversa etnometodológica atentam primordialmente para o como as coisas foram ditas. Portanto, métodos de coleta de dados que envolvam apenas observações com tomadas de notas não são suficientes. Para análises lingüístico-interacionais, não se pode confiar apenas em anotações e memória para lembrança de detalhes ocorridos nos turnos de fala (pausas, falas co-construídas, falas simultâneas, hesitações e outros fenômenos interacionais). É somente com dados gravados em áudio ( $\mathrm{e}$, em alguns casos, que não o desta pesquisa, também em vídeo) que analistas da conversa podem estudar os detalhes das reais interações (Silverman, 2001, p. 161).

Ainda dentro da tradição de estudos da análise da conversa etnometodológica, conforme explica Heritage (1984), o foco analítico (o que se analisará nos dados da interação coletados) é fortemente data-driven, ou seja, determinado a partir de fenômenos que são, de várias maneiras, evidenciados nos dados da interação. Segundo o autor,

há um forte preconceito contra especulações a priori sobre as orientações e motivações dos falantes e a favor de análise detalhada das reais ações dos interagentes. Sendo assim, a conduta empírica dos falantes é tratada como fonte central a partir da qual a análise pode ser desenvolvida. (p. 243)

Assim, os aspectos analisados não foram determinados $a$ priori, mas a partir dos fenômenos interacionais que aconteceram, de fato, na entrevista investigada.

\section{Resultados e discussão}

A partir da audição da entrevista e leitura da transcrição, ficaram evidentes dois aspectos principais, sobre os quais se discorrerá a seguir. Um deles é a assimetria de papéis interacionais/discursivos (quem pode fazer o quê) entre o entrevistado (aqui chamado de Ricardo) e a entrevistadora (denominada Alessandra). Tal assimetria é expressa sobretudo na condução da conversa por parte da entrevistadora, que determina os tópicos a serem explorados na entrevista, bem como os diferentes momentos da entrevista (até um determinado ponto é ela que pergunta; depois, explicitamente, dá o poder de questionamento ao candidato)

O outro aspecto analisado refere-se aos recursos lingüísticointeracionais utilizados pelo candidato no processo de gerenciamento de impressão, a saber: (1) aumento de velocidade de fala quando o entrevistado se refere à sua demissão ou outro evento descrito como negativo (fala mais rápida em relação ao contexto anterior e posterior da fala); (2) co-construção de turnos como forma de o entrevistado apresentar de antemão que conhece os assuntos, situações, descrições que são apresentados pela entrevistadora e (3) explicações (accounts) como forma de o candidato prevenir inferências negativas a seu respeito.

\section{Assimetria de papéis interacionais/discursivos}

A assimetria interacional é exercida por meio de diferentes fenômenos interacionais, tais como a escolha dos tópicos para a conversa por parte da entrevistadora Alessandra (A) e a interrupção que ela faz dos turnos da fala do entrevistado Ricardo (R). Também é ela quem direciona o evento discursivo (partes que comporão a entrevista, como no Excerto 1), quando Alessandra faz o anúncio de como a entrevista será realizada (candidato fala da experiência e depois ela fala da empresa). Uma vez que o candidato não responde da forma como esperava (linha 3), Alessandra diz, mais enfaticamente, o que ele deve fazer e falar.

Excerto 1:

1 A: ah::: e aí depois assim eu te passo mais a respeito dessa posição e da

2 empresa que que eles tão buscando tá bom?

3 R: oquei (obrigado)

4 A: pode começar a me falar da tua experiência

5 R: posso eu trabalhei sete anos na VVVV tá comecei como $<$ atendente $>$ de

6 loja

Como se pode observar no Excerto 1, já havendo determinado como a entrevista será conduzida, e obtendo uma concordância e, estranhamente, um agradecimento por parte do entrevistado, Alessandra passa à sua primeira pergunta (linha 4), que determina, também, o primeiro assunto que será tratado.

É também Alessandra quem tem o direito discursivo à interrupção da fala do outro, interrompendo o candidato para perguntar-lhe mais especificamente sobre um aspecto de sua fala, como é possível observar no Excerto 2.

Excerto 2:

$1 \mathrm{R}$ : assumi um cargo de supervisor passei a ser subgerente de loja (0.5) tá de

2 passei por várias lojas e tive experiência de várias equipes né vários gestores

3 diferentes ah::: até que (.) determinado momento me pas saram PRA > gerente

4 loja $<$ tá aonde fiquei um bom tempo também só que ah:: a empresa tá ela

5 optou por terceirizar suas lojas próprias (.) houve uma reestruturação e pra

6 que eu não fosse terceirizado=

$7 \mathrm{~A}:=i s s o$ foi $\langle$ quando $>$ ? 
8 R: isso foi agora em em:::::: outubro (2) é outubro do ano passado e como

9 houve essa reestruturação essa terceirização das lojas próprias ah:: eu fui

10 promovido pruma outra área tá?

Observa-se, na linha 7, uma interrupção da entrevistadora que redireciona a fala de Ricardo. Ricardo prontamente responde a essa pergunta (linha 8), mas imediatamente retoma o tópico iniciado na linha 6 , ou seja, o fato de ter sido promovido, o que, obviamente, parece algo positivo a ser dito sobre si em uma entrevista de seleção (Almeida, 2004; Silveira, 2002).

Aqui se concorda com Silveira (2002), que aponta para o fato de o entrevistador ter a legitimidade de introduzir todo e qualquer tópico pertinente à entrevista, bem como de julgar a completude e/ou pertinência das informações fornecidas pelo candidato, podendo dar por encerrado um determinado tópico desenvolvido por ele. Contudo, observa-se que, embora atenda às determinações da entrevistadora sobre o que deverá ser falado, o entrevistado encontra espaço para fazer retomadas que poderão ter repercussão positiva a seu respeito (como a de continuar a desenvolver o assunto que culminaria na informação sobre sua promoção).

No Excerto 3, ocorre o mesmo fenômeno de direcionamento da fala do entrevistado (linha 5), quando Ricardo abandona o que falava para voltar-se ao tópico introduzido pela entrevistadora (linha 6). Ela sublinha um tópico e direciona a conversa, sendo prontamente atendida pelo candidato.

Excerto 3:

1 A: tá e a tua equipe eram quantas pessoas

2 R: começou com nove tá e encerrou com trinta e quatro pessoas tá cresceu

3 muito e acredito que vai crescer mais ainda agora tá que a gente tava

4 trabalhando com outras redes que até então não trabalhava com VVVV

5 como (nome de empresa) como (nome de empresa) (já tava $\mathrm{XXX})=$

$6 \mathrm{~A}:=$ eram contas corporati:vas

7 R: não não não eram contas corporativas existiam dois perfis dentro

A partir da linha 2, o entrevistado discorre sobre o crescimento da sua equipe, assunto que apresenta positivamente o perfil do candidato, mas, na linha 6 , a entrevistadora introduz o tópico "contas corporativas". Nesse momento, Ricardo abandona seu tópico anterior e produz um turno que atende ao desvio proposto por Alessandra. Fica evidente, neste momento, a necessidade do candidato de submeter-se às conduções da interação feitas pela entrevistadora, abrindo mão de seu tópico para seguir aquele por ela proposto. Não há confronto sobre os tópicos a serem discutidos, já que o candidato prontamente deixa seu assunto para discorrer sobre aquele indicado por Alessandra e, diferentemente do que se observou no excerto anterior, dessa vez, não retoma o assunto sobre o qual discorria anteriormente.

\section{Gerenciamento de impressão}

Aumento de velocidade de fala na descrição de eventos negativos. Observou-se o recurso de aumento da velocidade de fala (fala mais rápida em relação ao contexto anterior e posterior da fala) em momentos muito específicos da fala do entrevistado. Esses momentos são o que denominamos descrição de eventos negativos, tais como quando o entrevistado se refere à sua demissão. A utilização desse recurso pode ser observada nos Excertos 4 e 5 .

\section{Excerto 4:}

1 R: a área de varejo tá onde eu fui o efetivo de vendas gerente de contas né e

2 eu fiquei até o dia seis agora do:::: mês de::: maio > fui desligado< também

3 passei por um outro processo de reestruturação não só eu como outros

4 colegas também foram desligados $>$ dessa vez eu não tive como escapar $<$

Excerto 5:

1 A: e porque tu saiu de lá?

2 R: houve na época tá uma baixa de remuneração na variável tá de tá na

3 comissionamento como eu tava acostumado a ganhar um valor bom o salário

4 medida em que vai reduzindo ta tu não gosta muito $>$ dai eu optei em sair<

No Excerto 4, verifica-se o fenômeno nas linhas 2 e 4 e, no Excerto 5, o fenômeno acontece na linha 4. Os extratos "fui desligado", “dessa vez eu não tive como escapar” e "daí eu optei em sair" são rapidamente falados pelo entrevistado, de forma a dar a impressão de que talvez não quisesse falar sobre isso.

Apesar de o candidato citar, no Excerto 5 (linha 4), que foi ele quem optou por sair de um de seus empregos anteriores, o assunto tratado nesse momento da entrevista refere-se a passagens por empresas. Independente de ter sido uma decisão tomada por Ricardo, o fato de ter permanecido pouco tempo em cada organização é um ponto sentido como negativo por ele, o que está em conformidade com os resultados de Silveira (2002), que menciona que candidatos marcam, em entrevistas de seleção, o fato de terem permanecido nos empregos anteriores por um bom espaço de tempo.

Co-construção de turnos. Segundo Lerner (1991; 1996; 2002), a co-construção de turnos de fala acontece quando dois interagentes constroem uma única idéia dentro de um mesmo turno de fala. Isto é, um segundo interagente colabora com uma segunda parte de um turno ainda em construção pelo primeiro interagente. A primeira parte do turno Lerner (1991) chama de componente preliminar, enquanto denomina a segunda componente final.

Nos dados analisados para este estudo, observa-se que, com certa freqüência, Ricardo utiliza o recurso de co-construção de turno. $\mathrm{O}$ interessante, nessa interação entre candidato e 
entrevistadora, é que o papel discursivo de co-construtor do turno do outro só acontece com Ricardo. Em outras palavras, Alessandra nunca termina um turno de Ricardo. Além disso, o recurso não é utilizado por Ricardo em qualquer circunstância, mas nos momentos específicos em que Alessandra descreve a empresa, seu funcionamento, seus procedimentos.

Dessa forma, Ricardo parece utilizar esse recurso como forma de antecipar para Alessandra seu conhecimento prévio sobre a empresa ou, em outras palavras, que fez sua tarefa de candidato (obter informações sobre dados e funcionamento da empresa, anteriormente ao momento da entrevista). Isso ocorre no Excerto 6.

Excerto 6:

1 A: bom Ricardo, eu vou te falar então assim um pouquinho da:: da empresa do

2 que eles tão buscando é um pouco diferente do que tu $>$ vem fazendo $<$

3 embora seja executivo de vendas tá é pra área de ti ah:: é uma empresa de

4 software então é pra vender software

5 R: certo

6 A: só que a venda também é: um pouco diferente porque os clientes são

7 corporativos né é um valor ah::: de software bem mais alto então são vendas

8 que $=$

$9 \mathrm{R}:=$ tem que ser bem trabalhado=

$10 \mathrm{~A}$ : =se estendem por: muitos meses né enfim

11 R: negociação mais=

$12 \mathrm{~A}:=$ exato ah é diferente do varejo=

$13 \mathrm{R}$ : =com certeza é a venda na hora

14 A: exato

$15 \mathrm{R}: \mathrm{XX}$ venda mais trabalhada

16 A: a pessoa saiu ali já ah:: com

17 R: dificilmente alguém vai compra um software na hora

18 A: não [XXX]

$19 \mathrm{R}: \quad$ [exatamente]

20 A: então é um pouco diferente até a linguagem assim essa empresa é uma

21 empresa nova tá desde dois mil no mercado é uma empresa gaúcha e eles

22 não tem a parte de vendas mas é uma empresa que o produto é muito bom

23 quem que eles têm como cliente ricardo? a rede (nome de empresa) tá (nome de

24 empresa) aqui no Brasil e em Portugal o (nome de empresa), enfim empresas $\mathrm{ah}=$

$25 \mathrm{R}:=$ de grande porte

26 A: EXATO esse é o foco uma empresa pequena ou média não tem condições

27 de arcar com os custos desse softwares tá

No Excerto 6, o fenômeno da co-construção de turnos aparece nas linhas $8,9,10,11,12,13$ e 24 e 25, além de haver uma sobreposição de falas nas linhas 18 e 19. Observa-se que o fenômeno ocorre após a entrevistadora marcar a diferença entre as exigências que o cargo ao qual o entrevistado candidatou-se possui e as experiências prévias do candidato. Num primeiro momento, ele concorda com a entrevistadora (linha 5) e, em seguida, começa a co-construir turnos de fala, nos quais, ao participar ativamente das explicações de Alessandra, antecipa à fala da entrevistadora o seu conhecimento prévio.

Observa-se, também, por parte de Alessandra, a necessidade de marcar a qualidade dos produtos da empresa contratante (linha 22), os grandes clientes dessa organização (linhas 23 e 24), além de deixar claro que não é qualquer empresa que pode contar com o software vendido (linhas 26 e 27), o que também pode ser compreendido como gerenciamento de impressão por parte da entrevistadora.

Explicações (accounts) como prevenção de inferências negativas. Estudos em análise da conversa de base etnometodológica enfatizam a centralidade do conceito de accountability em interações (Sacks, 1992). Analistas da conversa sugerem que os interagentes estão a todo tempo, em suas interações com os outros, fornecendo explicações (ou accounts) sobre as suas ações, de forma a evitar inferências negativas a seu respeito. Em outras palavras, tentam fazer com que suas construções de versões sobre a realidade pareçam sólidas e não-problemáticas, usando a linguagem para construir versões do mundo social (Potter, 1996).

Esse fenômeno também foi observado por Silveira (2002), que apresenta a utilização recorrente de explicações (do tipo escusa ou justificativa) por parte de candidatos, sobretudo em respostas a perguntas sobre saída de outras organizações.

$\mathrm{Na}$ entrevista analisada aqui, verificou-se que o candidato utiliza a estratégia de explicações, tentando minimizar o fato de ter sido demitido, por meio de menção às outras demissões ocorridas na empresa no mesmo período (linhas 2 e 3 do Excerto 4). Ao falar de sua demissão, o candidato vale-se de explicação (ou account) combinada com o aumento da velocidade de fala: "eu fiquei até o dia seis agora do :::: mês de ::: maio $>$ fui desligado< também passei por um outro processo de reestruturação não só eu como outros."

No Excerto 5, observa-se outro tipo de combinação de estratégias. Ao discorrer novamente sobre situações que podem ser julgadas como negativas a seu respeito, Ricardo produz uma explicação combinada com a utilização do pronome $t u$ (linha 4).

É interessante observar-se que, ao invés de colocar a si próprio como quem não gostou que seu salário fosse diminuído, o que poderia, em alguns contextos, gerar uma imagem negativa a seu respeito, Ricardo utiliza o pronome $t u$, em seu uso genérico. Tal estratégia retira de si a responsabilidade única sobre essa insatisfação, diluindo e generalizando entre todas as pessoas, em geral, o sentimento de frustração com a redução de salário.

\section{Considerações finais}

Com os dados apresentados, fica evidente a assimetria de papéis discursivos entre o entrevistado e a entrevistadora, expressa sobretudo nas ações da entrevistadora, que determina a agenda de tópicos a serem explorados na entrevista e, muitas vezes, interrompe os turnos de fala do entrevistado, reconduzindo 
a interação para os assuntos por ela deliberados. A microanálise dos dados da fala-em-interação entre entrevistadora e entrevistado também revela as estratégias discursivas de gerenciamento de impressões por parte do candidato no momento da entrevista de seleção, realizadas através dos fenômenos de: (1) aumento de velocidade de fala quando o entrevistado se refere à sua demissão ou a outro evento descrito como negativo (fala mais rápida em relação ao contexto anterior e posterior da fala); (2) co-construção de turnos como forma de o entrevistado apresentar que conhece alguns pontos apresentados pelo entrevistador e (3) uso de explicações (accounts) como recurso discursivo do candidato para prevenir inferências negativas a seu respeito.

Os achados aqui expostos contribuem para estudos sobre recrutamento e seleção de pessoas, fornecendo subsídios para as práticas de psicólogos e outros profissionais. A partir da descrição e discussão dos fenômenos abordados neste artigo, contribui-se para o corpo de estudos existentes sobre o tema.

Percebe-se, com este estudo, que a análise da conversa etnometodológica pode ser utilizada como instrumental analítico para melhor compreensão da situação de seleção de candidatos a empregos, uma vez que possibilita ao pesquisador identificar fenômenos apenas acessíveis pela análise de dados gravados e refinadamente transcritos. Dessa forma, apresenta-se para a Psicologia a importância e produtividade das ferramentas da análise da conversa de base etnometodológica, visto que fornecem subsídios para aprimoramentos de processos seletivos em organizações.

Cabe ressaltar, finalmente, que não se busca aqui generalizações sobre entrevistas de seleção para emprego, mas uma reflexão sobre a importância da ordem microetnográfica da fala, ou seja, uma reflexão sobre fenômenos de ordem interacional, que desloca a preocupação costumeira na Psicologia com o quê é dito, para deter-se em como é dito, foco analítico este ainda pouco explorado na área.

\section{Referências}

Almeida, W. (2004). Captação e seleção de talentos. São Paulo: Atlas.

Atkinson, P., \& Heritage, J. (Orgs.). (1984). Structures of social action: studies in conversation analysis. Nova York: Cambridge University Press.

Button, G. (1992). Answers as interactional products: two sequential practices used in job interviews. In P. Drew \& J. Heritage (Orgs.), Talk at work: interactions and institutional settings (pp. 212-231). Cambridge, Massachusetts: Cambridge University Press.

Carvalho, M. L., \& Grisci, C. L. I. (2002). Gerenciamento de impressão na seleção de pessoal: construindo estilos de vida contemporâneos. Revista Eletrônica de Administração - REAd, 4(8), 72-85.

Clegg, S. (1996). Poder, linguagem e ação nas organizações. In O. L. S. Torres (Org.), O indivíduo na organização: dimensões esquecidas (pp. 47-66). São Paulo: Atlas.

Drew, P. (2003). Comparative analysis of talk-in-interaction in different institutional settings: a sketch. In P. J. Glenn, C. D. Lebaron, \& J. Mandelbaum (Orgs), Studies on language and social interaction (pp. 293308). Mahwah, New Jersey: Erlbaum.

Erickson, F., \& Shultz, J. (1982). The counselor as gatekeeper: social interaction in interviews. Nova York: Academic.

Goffman, I. (1985). A representação do eu na vida cotidiana. Petrópolis: Vozes.
Heller, M. (2001). Discourse and interaction. In D. Schiffrin, D. Tannen, \& H. E. Hamilton (Orgs.), Handbook of discourse analysis (pp. 250-264). Malden, Massachusetts: Blackwell.

Heritage, J. (1984). Garfinkel and ethnomethodology. Cambridge: Polity.

Hutchby, I., \& Wooffitt, R. (1998). Conversation analysis: principles, practices and applications. Cambridge: Polity.

Jaworski, A., \& Coupland, N. (Orgs.). (1999). The discourse reader. Nova York: Routledge.

Lerner, G. (1991). On the syntax of sentences-in-progress. Language in Society, 20, 441-458.

Lerner, G. (1996). On the "semi-permeable" character of grammatical units in conversation: conditional entry into the turn space of another speaker. In E. A. Schegloff \& S. Thompson (Orgs.), Interaction and grammar (pp. 238-275). Cambridge, Massachusetts: Cambridge University Press.

Lerner, G. (2002). Turn-sharing: the choral co-production of talk-in-interaction. In C. E. Ford, B. A. Fox, \& S. A. Thompson (Orgs.), The language of turn and sequence (pp. 225-256). Nova York: Oxford University Press.

Levinson, S. (1992). Activity types and language. In P. Drew \& J. Heritage. (Orgs.), Talk at work: interactions and institutional settings (pp. 66-100). Cambridge, Massachusetts: Cambridge University Press.

Mendonça, J. R., \& Amantino-de-Andrade, J. (2003). Gerenciamento de impressões: em busca da legitimidade organizacional. Revista de Administração de Empresas - RAE, 43(1), 36-48.

Ostermann, A. C. (2006). Gênero, violência e sexualidade: uma investigação sociolingüistica interacional dos atendimentos à saúde da mulher. Manuscrito não-publicado [Projeto de Pesquisa CNPq 311288/2006-5], Universidade do Vale do Rio dos Sinos, São Leopoldo.

Pomerantz, A., \& Ferh, B. J. (1997). Conversation analysis: an approach to the study of social action as sense making practices. In T. van Dijk (Org.), Discourse as social interaction, (vol. 1; pp. 64-91). Londres: Sage.

Potter, J. (1996). Representing reality: discourse, rhetoric and social construction. Londres: Sage.

Potter, J. (2004). Discourse analysis as a way of analysing naturally occurring data. In D. Silverman (Org.), Qualitative research: theory, method and practice (pp. 200-221). Londres: Sage.

Potter, J., \& Wetherell, M. (1994). Analyzing discourse. In A. Bryman, \& B Burgess (Orgs.), Analyzing qualitative data. Londres: Routledge.

Ribeiro, B. T., \& Garcez, P. M. (Orgs.). (2002). Sociolingüística interacional. São Paulo: Loyola.

Sacks, H. (1992). Lectures on conversation. Oxford: Blackwell.

Schegloff, E. (1997). Confirming allusions: toward an empirical account of action. American Journal of Sociology, 102, 161-216.

Scheuer, J. (2001). Recontextualization and communicative styles in job interviews. Discourse Studies, 3(2), 223-248.

Schnack, C., Pisoni, T., \& Ostermann, A. C. (2005). Transcrição de fala: do evento real à representação escrita. Entrelinhas, 2, 2.

Schneider, B. (2000). Managers as evaluators: invoking objectivity to achieve objectives. The Journal of Applied Behavioral Science, 36(2), 159-173.

Silveira, S. B. (2002). Entrevistas de emprego: gerenciamento de tópico e de face. Palavra, 8, 209-235.

Silverman, D. (2001). Interpreting qualitative data: methods for analysing talk, text and interaction. Londres: Sage.

Ten Have, P. (1999). Doing conversation analysis: a practical guide. Londres: Sage.

Wetherell, M. (1998). Positioning and interpretative repertoires: conversation analysis and post-structuralism in dialogue. Discourse \& Society, 9(3), 387-412.

Wilkinson, S. (2003). Feminist contributions to critical health psychology. In M. Muray (Org.), Critical health psychology (pp. 83-100). Nova York: Palgrave Macmillan.

Wooffitt, R. (2005). Conversation analysis and discourse analysis: a comparative and critical introduction. Londres: Sage. 
${ }^{1}$ Neste artigo utilizaremos os termos entrevistador, entrevistado e candidato no gênero gramatical masculino para nos referirmos tanto a pessoas do sexo masculino como do feminino.

${ }^{2}$ Entende-se como gatekeeping toda situação de fala-em-interação em que um dos interagentes tem o poder de decisão sobre qual informação poderá ser dita ou não, que seqüência dar à fala, etc. São exemplos de situações de gatekeeping inquéritos policiais, triagens médicas, etc.

${ }^{3}$ Embora este artigo trate exclusivamente do gerenciamento de impressão por parte do candidato, Carvalho e Grisci (2002) salientam que este fenômeno também ocorre com entrevistadores, quando procuram passar uma imagem de profissional competente, sublinhar os pontos positivos das empresas contratantes, etc.

Caroline Benevenuti Passuello, mestre em administração pela Universidade do Vale do Rio dos Sinos, é consultora na Det Norske Veritas. Endereço para correspondência: Rua Cayowáa, 702, Ap. 91; São Paulo, SP; CEP: 05018-001. Tel./Fax: (51) 9833-9130. E-mail: carolpassuello@hotmail.com Ana Cristina Ostermann, doutora em lingüística pela University of Michigan (EUA), é professora adjunta na Universidade do Vale do Rio dos Sinos. E-mail: aco@unisinos.br 


\section{Anexo}

\section{Convenções de transcrição}

As convenções utilizadas na transcrição são as traduzidas e adaptadas por Schnack, Pisoni e Ostermann (2005) a partir das convenções propostas por Gail Jefferson, em Atkinson e Heritage (1984).

\begin{tabular}{|l|l|}
\hline$[$ texto] & falas sobrepostas \\
\hline$(1.8)$ & pausa, com o tempo da pausa entre parênteses \\
\hline$()$. & micropausa, com menos que 0.2 segundos de ausência de fala \\
\hline$=$ & fala colada \\
\hline, & entonação contínua \\
\hline$\cdot$ & entonação descendente \\
\hline$?$ & entonação ascendente \\
\hline- & interrupção abrupta da fala \\
\hline$:$ & alongamento de som \\
\hline$>$ texto< & fala mais rápida \\
\hline$<$ texto $>$ & fala mais lenta \\
\hline TEXTO & fala com volume mais alto \\
\hline$@ @ @ 0$ & pulsos de risadas \\
\hline texto) & dúvidas na transcrição \\
\hline XXXX & fala inaudível \\
\hline itálico* & parte da interação que o analista quer destacar para o leitor \\
\hline
\end{tabular}

(*) O negrito, proposto originalmente por Schnack, Pisoni e Ostermann (2005), foi substituído por itálico no presente artigo, para atender ao padrão adotado nas normas para publicação (APA). 